challengos of cosmology: to determine which aspects of the universo can be explained with the known laws of physics, and which aspacts require entirely new concepts. After a somewhat historical sketch of the theoretical foundations of cosmology, he describes the optical and radio background with emphasis on quasi-stellar objects, intergalactic matter, and the microwave radiation. Then he compares further aspects of the theory with these observations and discusses the problem of the origin of matter. Although we can meaningfully describe the behaviour of existing cosmic matter with known physics, McCrea concludes that this is not the case for the origin of matter which "may be a more fitful process than hither'to envisaged". This essay contains deep insights into cosmology and is a dolight to ponder.

The publisher motivates the slim size of these volumes by claiming it makes them more likely to bo read. $\mathrm{He}$ seems to have gone rather far in this respect, because every other page is an absolute blank. The typography and offset printing of those pages which do contain text are rather mediocre. At a cost of more than two shillings per page of text, the real motives of the publisher are painfully clear. I have detached one of these pages, weighed it, and found that it costs more than the same weight of pure silver.

The publisher would do the scientific and technical community a great service by ceasing to issue forthcoming surveys in this series in this expensively absurd format. The natural medium for such short survey articles is one of the many journals which publish them. These two articles should, however, be read for an up to date appreciation of the problems in understanding the behaviour of the universe on its grandest scale.

William C. Saslaw

\section{THE COMPLEX WORLD}

\section{Physics of the Earth}

By Frank D. Stacey. (Space Science Text Series.) (Wiley : New York and London, January 1970.) Pp. xi +324. $105 s$.

\section{Physics of the Earth}

By 'T. F'. Gaskell. ('The World of Science Library.) Pp. 216. (Thames and Hudson: London, January 1970.) $42 s$ boards; $21 s$ paper.

THE physicist, coming to a study of the Earth for the first time, is likely to feel perplexed and even a little unhappy. For one thing, he will find that he is no longer dealing with pure substances or carcfully controlled phenomena amenable to laboratory experiment, but with complex and frequently inaccessible materials which lose all significance out of their natural context. And, as if the Earth were not formidable enough as an object of study in its present state, the new recruit to geophysics will find the burden of the Earth's past pressing on him. For the Earth today is only explicable in terms of its total history; and thus the rationale of the historic sciences must be added to, and combined with, that of the physical sciences in which the configurational plays little part. As a result, rigorous analysis is often impossible, nebulous data tend to mushroom into speculative hypotheses, and order of magnitude calculations appear as theories. It is a field in which vast intellectual edifices can be, and often are, built on a handful of observations.

But the geophysicist must make the best of a very complex world--and, in truth, he has not done at all badly. It is thus right that he should, from time to time, present his conception of the Earth for inspection in a single concise volume. It is now ten years since this was last done-a decade of unprecedented discovery in the geosciences. Stacey is surely correct in suggesting that palaeomngnetism has produced a "rovolution in geophysical thinking . . . caused by establishing continental drift as an acceptable hypothesis after decades of general disfavour". Contincntal drift, in turn, led to the idea of convection currents in the mantle, and that led directly to sea floor spreading and plate tectonics. Today's picture of a mobile Earth would hardly be recognized by the geoscientists of even twenty years ago.

In a well written, very readable scientific text, Stacey has summarized our present state of knowledge of the Earth. All the usual fields are covered-gravity, seismology, geomagnetism, palaeomagnetism, mantle properties and heat flow-and each is shown to add something to the new global tectonics. I have no hesitation whatsoever in recommending this book; but in so doing $\mathrm{I}$ am prompted to ask myself to whom precisely am I recommending it. This question is not quite as silly or cynical as it might seem, for there is a genuine dilemma here, though not, of course, of Stacey's making. Our knowledge of the Earth is now so vast that any attempt to condense it into less than three hundred pages of text must inevitably lead to sorne oversimplification. There is thus a conflict between detail and space available which left me with the feeling that a book of this type falls uncomfortably between two stools. On the one hand, the established geophysicist will know the story already, while on the other, the new student of the field will not find the material detailed enough for the courses he may be taking. Thus, while the book is admirable within its own terms of reference, those terms may lead to use of the book for collateral reading rather than for detailed study at undergraduate level.

Gaskell's book, though covering much of the same ground, is intended for a rather different audience-the much-wooed layman. Again the text is well written, eminently readable, though non-mathematical. But the working scientist would be quite wrong in thinking that there is nothing here for him. As one might have guessed from the name of the publisher, this book is heavily endowed with photographs, many in colour. The average geophysicist is almost certainly photo-starved and there is thus much pleasure to be had in putting away the mathematical models for an evening and looking at the Earth's features as they really are. My own favourite, apart from the now famous view of the Earth from Apollo 8 , is a beautiful colour photograph of exposed Permian coal seams in Antarctica. But beauty is in the eye of the beholder, they say, and other eyes may marvel at other things. They will certainly find something here to marvel at. Peter J. SMIth

\section{SALTY HOLES IN THE RED SEA}

\section{Hot Brines and Recent Heavy Metal Deposits in the Red Sea}

Geochernical and Geophysical Account. Edited by Egon T. Degens and David A. Ross. Pp. xii +600 . (SpringerVerlag: Berlin, Heidelberg and New York, 1969.) DM 128.

The hot salty holes in the Red Sea contain some of the most startling sediments yet described. Temperatures as high as $56^{\circ} \mathrm{C}$ and salinities $7 \frac{1}{2} \times$ normal have been measured in the sharply delineated layers of brine at the bottom of them: a corer lowered into them comes back still hot to touch, and its brightly coloured contents, layered red, white and blue, makes a welcome change to the geologist accustomed to drabber seafloor deposits. The six hundred large pages of this book contain fifty variegated papers devoted to their elucidation and potential exploitation. Moreover, the book is a rarity in the necessarily increasingly compartmentalized field of oceanography, because in it the skills of geophysicists, gcologists, biologists, geochemists, palaeontologists, physical oceanographers and mathematicians have all been applied, the lion with the lamb, to the solution of one problem: the origin of the hot brines. 